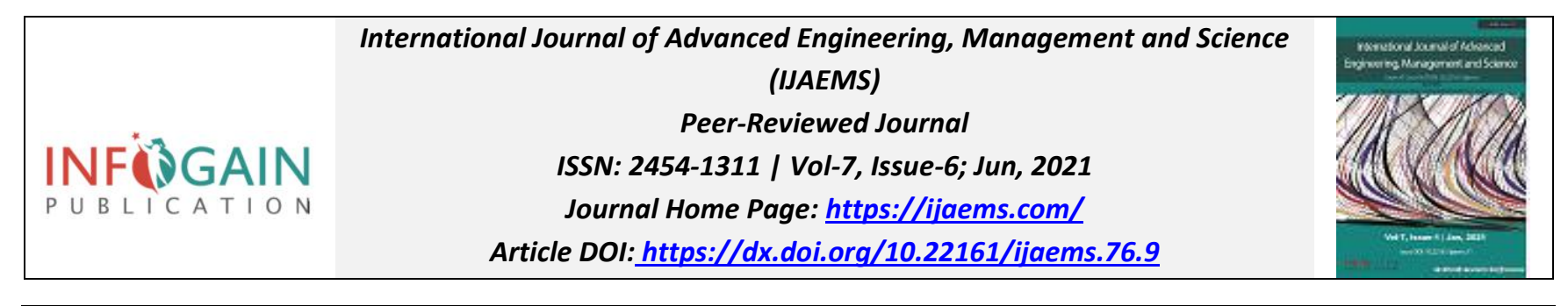

\title{
Effect of Covid-19 Pandemic among Rice Retailers in Nueva Ecija
}

\author{
Diana B. Magpale ${ }^{1}$, Louise Daphne A. Tabigne ${ }^{2}$, Ann Jellie G. Beley ${ }^{3}$, Ruby Ann C. \\ Estrella $^{4}$, Voltaire B. Angeles ${ }^{5}$, Felipe E. Balaria ${ }^{6}$
}

${ }^{1}$ Department of Education - Division of San Jose City, Philippines

${ }^{2}$ National Food Authority - Cabanatuan City, Philippines

${ }^{3} 1^{\text {st }}$ Megasavers - Cabanatuan City, Philippines

${ }^{4}$ Bulacan Agricultural State College - San Ildefonso, Bulacan, Philippines

${ }^{5}$ PDB Properties, Inc. - Makati City, Philippines

${ }^{6}$ Graduate School, Nueva Ecija University of Science and Technology, Philippines

Received: 09 Apr 2021; Received in revised form: 16 May 2021; Accepted: 04 Jun 2021; Available online: 16 Jun 2021

\begin{abstract}
This research studied the effect of the COVID 19 Pandemic on selected rice retailers in Nueva Ecija, Philippines. The researchers made use of guided survey questionnaires and phone calls to reach out to the 58 respondents of the study. The researchers found out that: Majority of the rice sellers considered themselves as greatly affected by COVID 19 Pandemic. Their diverse explanations were due to (a) the scheduling or selecting of those allowed to travel to the market, and (b) limiting kilos per person to serve the full town. Most of them stated that their sales decline by 50 percent at the time of COVID. Their financial issues were on collection rental payments and on wages of staff. Almost all of the rice retailers believe that their firm will survive even in these hard times. Regarding government aid, the majority of them indicated that they are not supported by the government while the remaining respondents claimed that they received help from the government and that the aid was given through the Pantawid Pamilyang Pilipino Program (4Ps).
\end{abstract}

Keywords-Challenges, COVID 19 Pandemic, Effect, NFA rice, rice retailers.

\section{INTRODUCTION}

COVID-19 has a significant impact on rice, which is one of the agricultural crops most affected. It has a major impact on labor, according to Balie (2020) [1], the International Rice Research Institute's (IRRI) Acting Director of Research and Agri-Food Policy. As a result, the product shortage is also due to a lack of manpower in some rice enterprises, and with only a few people to work, the next issue is rising labor expenses. Logistics is the second most important factor after labor. Rice dealers have found it difficult to deliver their products to different regions since the government imposed severe limits from one region to another. Problems with labor and logistics eventually lead to capital flow or liquidity shortages in the agricultural sector. This necessitates that the government addresses these issues as soon as possible in order to avoid This article can be downloaded from here: www.ijaems.com negative implications for planting and agricultural management.

Small farmers or vulnerable individuals should be financially assisted, according to a study by [2] titled, Effect of COVID-19 Pandemic on the Food Supply Chain, and governments should allow the mobility of workers and agri-food items. The government must consider measures for improving working conditions while safeguarding employee health and safety. To prevent the virus from spreading, the government must also examine the severity of the situation from province to province. Meanwhile, in the Philippines, all government agencies began to design a variety of policy decisions and preventive measures to secure the food supply and logistics in order to preserve its people from starvation. This simply goes to prove that the COVID-19 health catastrophe has various ties to the global

76

This work is licensed under a Creative Commons Attribution 4.0 License. http://creativecommons.org/licenses/by/4.0/ 
and local food systems. Despite the pandemic, Finance Secretary Carlos G. Dominguez III's advice of five urgent steps boosted domestic spending and re-energized the economy. The Build, Build, Build initiative encourages the creation of products with "strong and inelastic demand," particularly food production and logistics, as well as support for the entire food production value chain, including the establishment of food markets to facilitate distribution [3].

COVID-19 creates severe supply-chain disruption in terms of food demand and consumption, according to Palo, Rosetes, and Carion (2020) [4] in their study "COVID-19 and food systems in the Philippines." The researchers looked at four important food product chains in this assessment article: rice, pork, cabbage, and Lakatan banana. Focusing on rice, the Philippines' main food staple, the Department of Agriculture warned in March 2020 that there is a risk of severe rice shortages in the second half of 2020, which might be triggered by a slowdown in rice shipment from other adjacent countries. The Bayanihan to Heal as One Act (RA 11469) permitted local government entities to use their Calamity Funds to buy fresh rice directly from farmers at the start of COVID19 (in some cases, at a higher price than would be found at the market). Large quantities of rice were also purchased from cooperatives and other farming organizations by national organizations for distribution as part of relief packages in areas where rice production was non-existent (NCR and other highly urbanized areas). From March to June 2020 , these assistance packages of $2-5 \mathrm{~kg}$ of rice per home were provided with varying regularity.

As COVID 19 continues to wreak havoc in the Philippines, customers are less concerned about how the food on their tables is produced and more concerned about food safety. The government argued that the staff of various enterprises must be able to develop a food system that strictly follows COVID-19 health guidelines. It is past time for the general population to recognize the importance of agriculture. Consumers are becoming more aware of the complex relationship between what they eat and the quantity and quality of farm production, which could be used to encourage more government programs and budget allocation, as well as private agricultural initiatives such as farm-based small-and-medium enterprises. As a result, there is a pressing need to promote a widespread, sustainable, and responsible consumption pattern that sends strong signals to agricultural products that support and adhere to cleaner production, environmental conservation, and social inclusion [5]. Most farmers and assemblers indicate lowered sales and sales prices in a status report titled "Rapid assessment of the effect of COVID-19 on food supply chains in the Philippines" (January 2021) [6]. Direct internet selling to households is an exception to this trend, which appears to have provided chances for formal businesses. Retailers at wet markets and service facilities report drastically lower sales after an initial round of panic-induced shopping. In the modern retail category, however, the quarantines had a divergent effect, benefiting the top supermarkets. In Metro Manila, retail prices displayed a distinct pattern of initial volatility in the weeks leading up to and following the ECQ, followed by many weeks of more steady prices. The purpose of this study was to examine the impact of the COVID 19 epidemic on selected rice retailers in Nueva Ecija, as well as the issues that arose during the lockdown and up to the present, and the proposed remedies to these issues.

\section{METHODOLOGY}

This study utilized the basic descriptive research design [7] as cited in [8]. It described the rice retailers' challenges experienced with the effect brought by COVID 19 pandemic to their rice retailing business. The respondents of the study were asked to answer the guided survey questionnaire. They were also invited for a phone call interview. The respondents were determined using the purposive sampling technique. Only 58 rice retailers participated in the survey. Considering the quarantine protocols highly reinforced by the different municipalities of Nueva Ecija, the researchers were not able to invite respondents for every municipality in Nueva Ecija. As a result, the researchers have chosen seven nearby municipalities to ensure safety. Frequency, percentages, tables, and graphs were used to compute and present the data of this research.

\section{RESULTS AND DISCUSSION}

\section{Effect of COVID 19 Pandemic to Rice Retailers}

The respondents were asked to describe the effects of the COVID 19 Pandemic on their rice retailing business. They were given options such as greatly affected, moderately affected, slightly affected, and not affected at all. The figure below shows the results of their response to this question. 


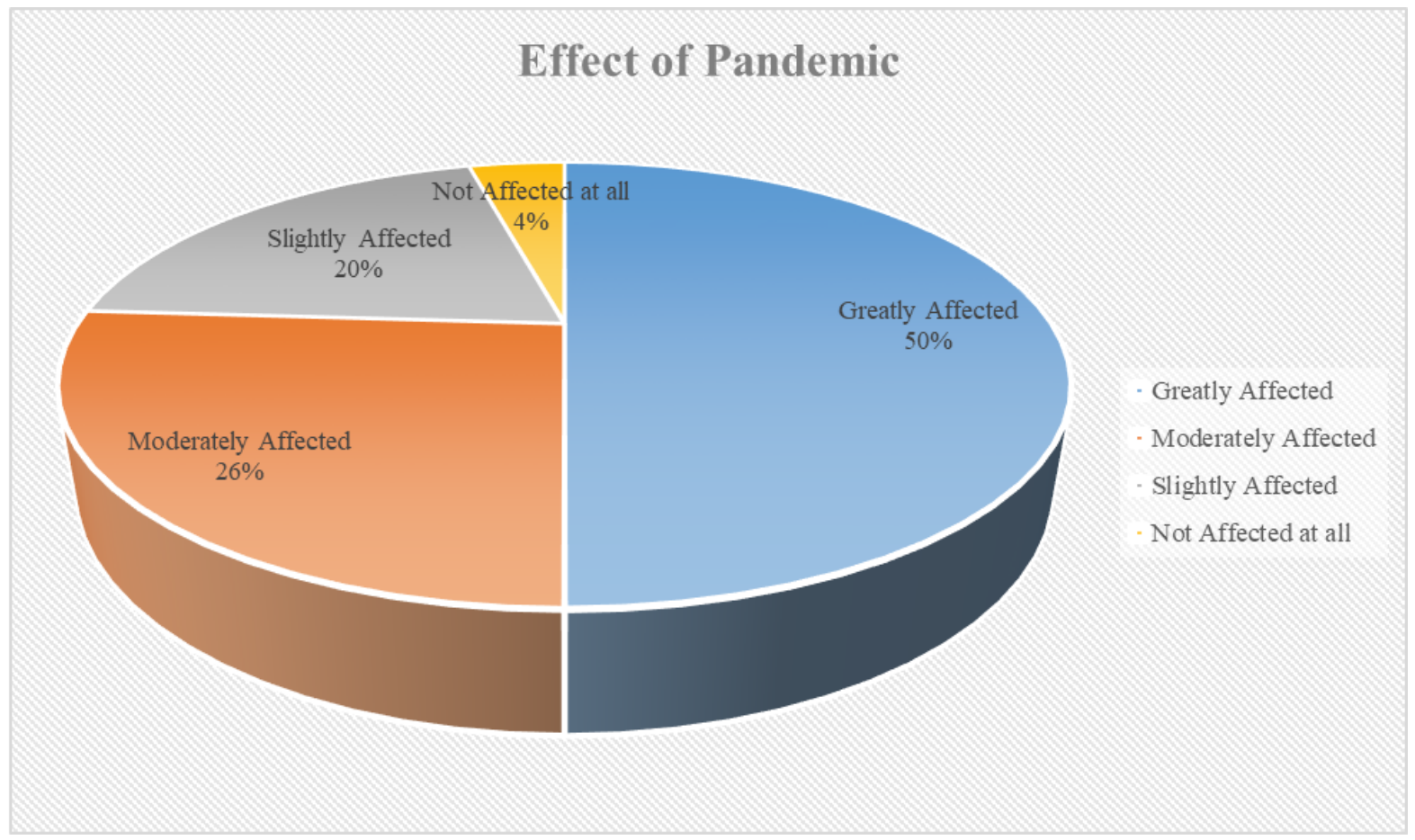

Fig.1: Effect of COVID 19 Pandemic Among the Rice Retailers

The pie graph reveals that $50 \%$ of the rice retailers consider themselves greatly affected by COVID 19 Pandemic. Their different reasons were because of: (a) the scheduling or selecting of persons allowed to go to the market (b) limited kilos per person to serve the whole municipality. In addition, $26 \%$ believe that they were moderately affected while $20 \%$ were slightly affected. Only $4 \%$ of the respondents said that their businesses were not at all affected by the pandemic.

\section{Sales of Rice During Pandemic}

When the respondents were asked regarding their sale situation during a pandemic, $67 \%$ honestly answered that their sales decrease during the time of COVID 19 while $33 \%$ said that they in fact increase with their sales even in the presence of the said pandemic.

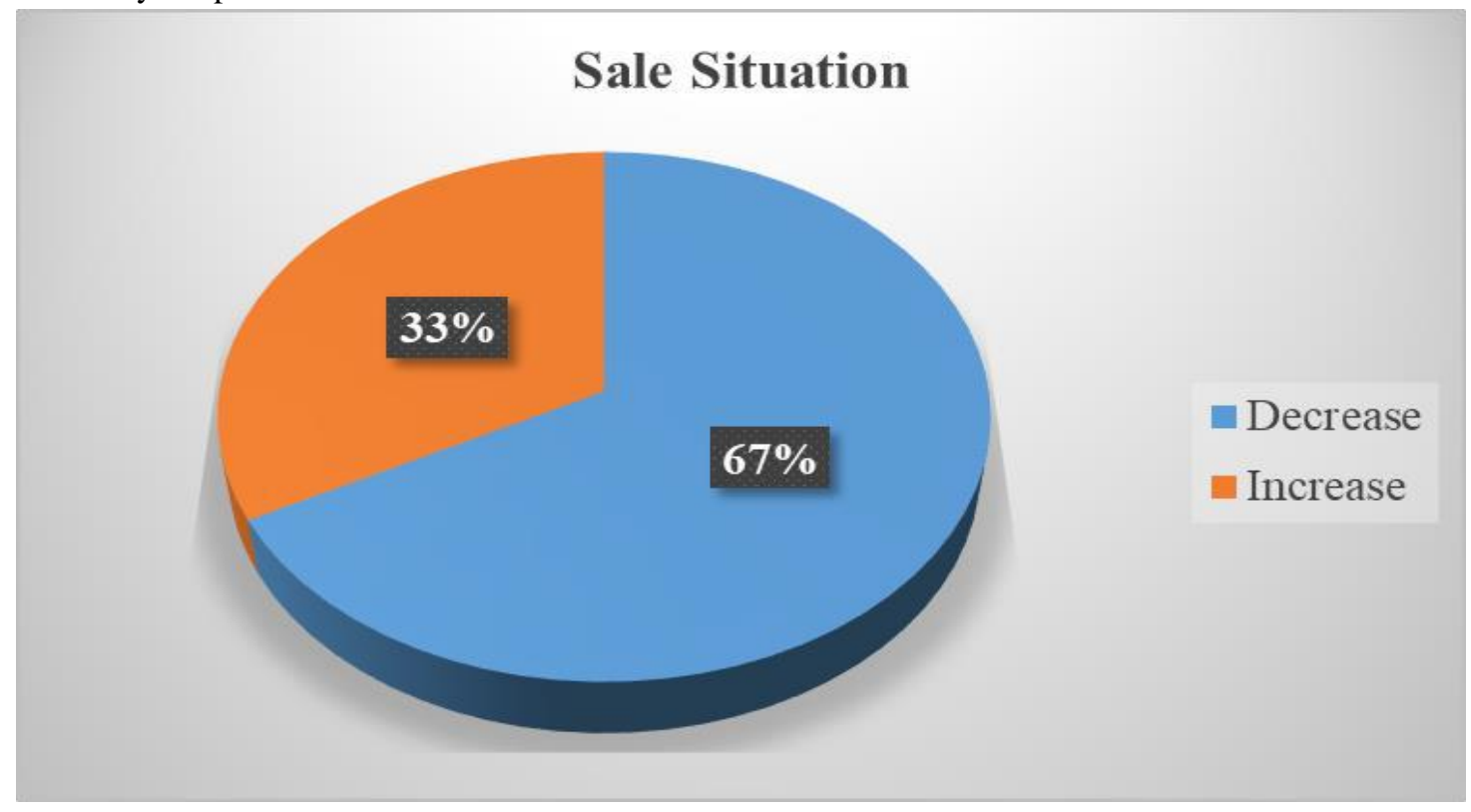

Fig.2: Sale Situation of Rice During Pandemic 
Those who answered yes, have stated that there was a 26 to $50 \%$ decrease in their sales when COVID 19 was nonexistent. This implies that the respondents reduce their sales by almost half of their profit compared with last year.

\section{Sales of Sack of Rice Before and During Pandemic}

Another area of concern was asked from the respondents; What is the average volume of sacks you sold per day before and during the pandemic? More than half of the respondents said that the average volume of their sales during the pandemic is $1-5$ sacks but before the pandemic it was 1-10 sacks of rice.

Table 1. Sales of Sack of Rice per Day before and during the Pandemic

\begin{tabular}{ccc}
\hline Percentage (Respondents) & $\begin{array}{c}\text { Before the Pandemic } \\
\text { (Sale of Sack of Rice per Day) }\end{array}$ & $\begin{array}{c}\text { During the Pandemic } \\
\text { (Sale of Sack of Rice per Day) }\end{array}$ \\
\hline $60 \%$ & $1-10$ & $1-5$ \\
$18 \%$ & $11-20$ & $6-10$ \\
$8 \%$ & $21-30$ & $11-15$ \\
$14 \%$ & 31 and above & $16-20$ \\
\hline
\end{tabular}

As regards the maximum sale of the sack of rice per day during the pandemic, the respondents stated that they only sell a maximum of 20 sacks per day when compared to the time before the pandemic which is 31 or more sacks of rice.

\section{Financial Problems During Pandemic}

Another realistic question asked from the respondents; What is the most significant financial problem your business is facing during the pandemic? $25.86 \%$ admitted problems on the collection, $24.14 \%$ on rental fees, $22.41 \%$ no problems encountered, $12.07 \%$ on wages of workers, $8.62 \%$ on earning loss, and $6.90 \%$ on loan payments.

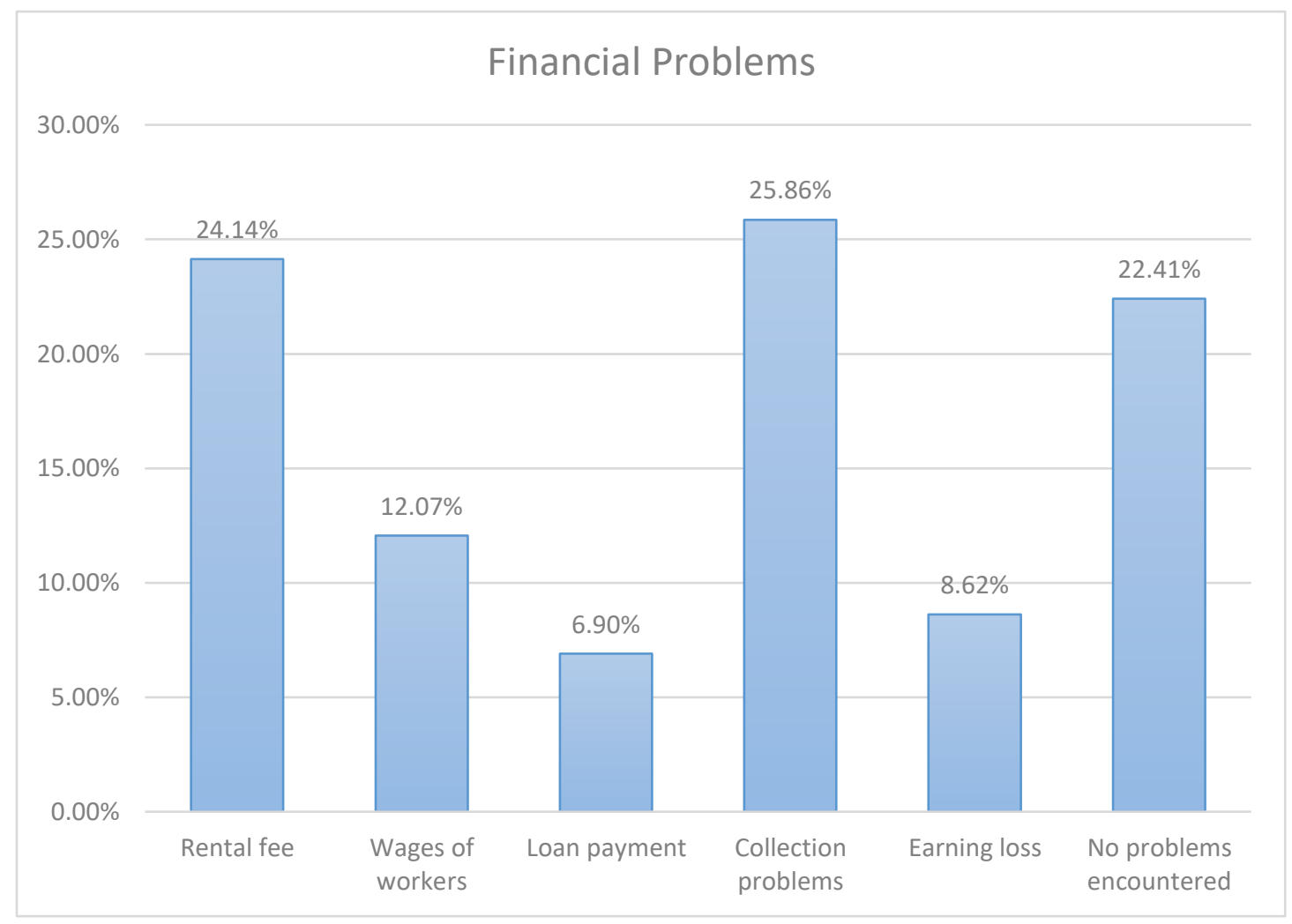

Fig.3: Financial Problems During Pandemic 
The researchers also posted an existential question; Do you think your business can survive if this pandemic will continue? $94.82 \%$ among the rice retailers steadfastly answered yes while $5.18 \%$ said No, their business will not survive these challenging times. Regarding government assistance, the researchers asked the respondents; Was there any assistance given to you by the government? $98.28 \%$ answered No, they are not supported by the government while $1.72 \%$ of the respondents answered Yes, they are receiving support from the government and that the assistance was given through the 4P's Government Program.

\section{Possible Solutions/ Interventions to Address the Problems}

When the respondents were asked what are the possible solutions to the challenges [9] that they are currently experiencing, the following strong points were highlighted: The government must assist rice retailers in lowering the price of rice purchased from rice millers and traders. Because of excessive rice importation from the private sector, the government should assist in increasing the number of local rice on the market, particularly during pandemics. Increased government assistance in relation to rice market prices. Local rice prices should be reduced with the support of each municipality's Local Government Units to make it more accessible for customers, especially during this epidemic.

\section{CONCLUSIONS AND RECOMMENDATIONS}

The majority of the rice retailers consider themselves greatly affected by COVID 19 Pandemic [10]. Their different reasons were due to: (a) the scheduling or selecting of persons allowed to go to the market; and (b) limited kilos per person to serve the whole municipality. Most of them answered that their sales decrease by $50 \%$ during the time of COVID. Their financial challenges were on collection rental fees and on wages of workers. Almost all of them believe that their business will survive these challenging times. Regarding government assistance, the majority of them stated that they are not supported by the government while other respondents mentioned that they are receiving support from the government and that the assistance was given through the 4P's Government Program. Possible solutions to the problems that the rice retailers are currently experiencing are the following: The rice retailers need the help of the government to decrease the price of rice coming from the rice millers/ traders. The government should help increase the number of local Rice in the market especially during a pandemic because of too much importation of rice from the private sectors.
Enhanced Government support with regards to the market price of rice. The price of local rice should be lessened through the help of the Local Government Units of each municipality to become affordable for the consumers especially during this time of the pandemic.

\section{REFERENCES}

[1] Balie, J. \& Valera, H. (2020). Is COVID19 a threat to the stability of rice price and supply? https://www.irri.org/news-and-events/news/covid19-threatstability-rice-price-and-supply

[2] Aday, S. \& Aday M., Effect of COVID-19 on the food supply chain, https://academic.oup.com/fqs/article/4/4/167/5896496

[3] Dy, R., (June 2020), Philippine agriculture and COVID-19 effect., $\quad$ https://www.bworldonline.com/philippineagriculture-and-covid-19-effect/

[4] Palo, A., Rosetes M., Carino D., (2020), COVID-19 and food systems in the Philippines. Foodlink Advocacy Cooperative, the Philippines. https://aciar.gov.au/publication/covid19/7-covid-19-andfood-systems-philippines

[5] Gregorio, G. \& Ancog, R., Assessing the Effect of the COVID-19 Pandemic on Agricultural Production in Southeast Asia: Toward Transformative Change in $\begin{array}{lll}\text { Agricultural } & \text { Food } & \text { Systems. }\end{array}$ https://doi.org/10.37801/ajad2020.17.1.1

[6] Situational report no 15 re Coronavirus Disease 2019ndrrmc.

[7] Jocson, E. J. C., Subia, E. G. S., \& Florencondia, E. N. T. (2019). Flood prevention and mitigation initiatives towards a flood-free city. American Scientific Research Journal for Engineering, Technology, and Sciences, 58(1), 215-224.

[8] Rogayan, D.V., Jr.; Dollete, L.F. Disaster awareness, and preparedness of Barrio community in Zambales, Philippines: Creating a baseline for curricular integration and extension program. Rev. Int. Geogr. Educ. Online 2020, 10, 92-114.

[9] Abelardo, L., Lomboy, M., Lopez, C., Balaria, F., \& Subia, G. (2019). Challenges Encountered by the National High School Teachers in Doing Action Research. International Journal of English, Literature and Social Science (IJELS), Vol-4, Issue-4, Jul $\quad$ - $\quad$ Aug 2019 https://dx.doi.org/10.22161/ijels.4418 ISSN:2456-7620.

[10] Mina, J., Subia, G., Pascuala, P., Tuliao, R. \& Pastorfide, D.(2020). Inclinations of Engineering and Marketing Management Students to Engage in Online Learning Technology Amidst the COVID-19 Pandemic. Technology Reports of Kansai University. ISSN: 04532198 Volume 62, Issue 09, October 2020 